\title{
MULTILETRAMENTOS NA PRODUÇÃO DO GÊNERO DISCURSIVO MARCADOR DE PÁGINA
}

Marcelo de Castro*

RESUMO: Este estudo, fundamentado nas teorias a respeito dos multiletramentos e dos gêneros discursivos, objetivou caracterizar e analisar como uma docente de Língua Portuguesa explorou a escrita do gênero discursivo multimodal marcador de página, em um evento de letramento, com alunos dos Anos Finais do Ensino Fundamental. Com isso se intencionou problematizar possibilidades e desafios que emergem de práticas dessa natureza em prol dos multiletramentos. Do ponto de vista metodológico, a investigação ocorreu por meio da observação participante da prática de uma professora em três turmas de $8^{\circ}$ ano, em uma escola pública de Ouro Preto (Minas Gerais). A partir disso, foi perceptível depreender possibilidades didáticas e discursivas, por exemplo, referentes à valorização das múltiplas linguagens em uma prática social de produção de um gênero discursivo composto por um projeto gráfico-visual. Além disso, foi possível discutir entraves inerentes às práticas multiletradas no ensino de Língua Portuguesa, como a escolarização de um gênero discursivo, o que implica mudanças de tecnologias e de recursos usados em processos de escrita.

PALAVRAS-CHAVE: Ensino de língua portuguesa; Gênero discursivo; Marcador de página; Multiletramentos.

\section{Introdução}

Street (2014), ao conceituar a multimodalidade como os vários modos de comunicação que existem, reforça que, nos dias atuais, o processo de ensino e aprendizagem da leitura e da escrita não pode deixar de considerá-la, portanto, deve ser objeto de discussão na escola em prol da recepção das linguagens de modo criativo e consciente. Sendo assim,

\footnotetext{
* Doutorando em Linguística Aplicada pela Universidade Federal de Minas Gerais (UFMG). Mestre em Educação pela Universidade Federal de Ouro Preto (Ufop). Docente da disciplina Oficina de Língua Portuguesa: texto e discurso, na Faculdade de Letras da UFMG.
} 
como menciona Dionisio (2011), ser letrado, nos dias de hoje, é ser capaz de ler e produzir significados provenientes de diversas linguagens.

Ao se considerar essa ideia, como objeto deste estudo, recorte de uma pesquisa mais ampla, foi escolhido um evento de letramento (HEATH, 1982), a partir de uma perspectiva da multimodalidade inerente aos gêneros discursivos, por se entender que o ensino de Língua Portuguesa, entre vários objetivos, busca tornar os estudantes mais proficientes na compreensão e na produção de textos multimodais. Por isso, o objetivo geral foi caracterizar e analisar como uma docente de Língua Portuguesa explorou a escrita do gênero discursivo multimodal marcador de página, em um evento de letramento, com alunos dos Anos Finais do Ensino Fundamental. Também se almejou, em consequência, problematizar possibilidades e desafios que emergem de práticas dessa natureza em prol dos multiletramentos.

Reforça-se, nesse contexto, a necessidade de se repensar o ensino de Língua Portuguesa com base em novas investigações teóricas e nas novidades em relação às práticas sociais de leitura e escrita, como afirmam muitos pesquisadores, como Dionisio (2011), Ribeiro (2016), Rojo (2009), Rojo e Barbosa (2015).

\section{Fundamentação teórica}

\section{Multiletramentos}

A Pedagogia dos Multiletramentos do Grupo de Nova Londres (GNL) cunhou o conceito de multiletramentos cujo prefixo "multi" indica tanto a multiplicidade de linguagens (foco desta investigação) quanto a diversidade cultural (COPE; KALANTZIS, 2006). Essa pedagogia reelaborou a ideia (anacrônica e não condizente com a realidade hodierna) de que as práticas sociais de leitura e escrita estão restritas à linguagem verbal, a fim de reconhecer e considerar a dinamicidade dos vários modos de comunicação (como as representações visuais, auditivas, gestuais, espaciais e táteis) presentes nas práticas letradas.

Segundo Cope e Kalantzis (2009), a imagem, por exemplo, aparece mais em livros, revistas e jornais, e, nesses casos, a complexidade da linguagem verbal pode diminuir, ou 
seja, tem-se suavizado a carga de sentidos sobre a palavra, por outro lado, novas complexidades passam a existir via representações multimodais. Isso exige que a mesma atenção que se deu à linguagem verbal também recaia a outros modos semióticos. Sobre essa questão, salienta-se que a linguagem verbal escrita não está sumindo, mas somente se tornando ainda mais entrelaçada com outros modos semióticos. Esse apontamento de Cope e Kalantzis (2009) reforça, pois, a urgência da escola letrar os alunos para além da linguagem verbal, isto é, a necessidade de se multiletrar.

Cope e Kalantzis (2006) argumentam que o multiculturalismo, a migração e a conectividade econômica global tornam mais intensos os processos de mudanças linguísticas e culturais de determinado local. Quanto a isso, discutem três dimensões que devem ser levadas em consideração em uma apropriada educação linguística contemporânea, numa abordagem pluralista das culturas e das linguagens: a diversidade produtiva (no âmbito do trabalho), o pluralismo cívico (no âmbito da cidadania) e as identidades multifacetadas (no âmbito da vida pessoal).

Quanto à vida do trabalho, tais autores defendem a diversidade produtiva, uma vez que as relações trabalhistas, a natureza das organizações e as tecnologias se apresentam com novidades, o que tem produzido uma recente linguagem de trabalho. Com isso as exigências do mercado de trabalho também são outras e os professores precisam trabalhar com as várias linguagens em uso dinâmico, inovador e criativo, assim como possibilitar a entrada dos alunos no mercado de trabalho como sujeitos capacitados para "falar, para negociar, e para serem capazes de se envolverem criticamente com as condições de vida profissional deles"13 (COPE; KALANTZIS, 2006, p. 13, tradução nossa). No que se refere à vida pública, se o mundo do trabalho e as questões geopolíticas estão em constante mudança, a cidadania também acompanha esse processo. Logo, a pluralidade linguística e a cultural

13 "speak up, to negotiate, and to be able to engage critically with the conditions of their working lives" (COPE; KALANTZIS, 2006, p. 13). 
têm papel central e, nessa perspectiva, os estudantes precisam, por exemplo, negociar dialetos regionais, adequar o uso linguístico de acordo com o contexto social, aprender diferentes significados da linguagem visual e gestual. Por último, Cope e Kalantzis (2006) argumentam que a vida particular de cada indivíduo tem se tornado mais pública, principalmente graças ao uso que se faz dos meios de comunicação de massa. Além disso, as pessoas não são mais membros de um único grupo, porque se engajam em diferentes modos de vida, evidentemente, em diversas comunidades a respeito de trabalho, etnia, gostos, sexualidade etc. Isso também é um desafio para o letramento, uma vez que, com muitas identidades, as fronteiras entre estas são mais opacas, o que torna necessário reconhecer a existência de várias identidades multifacetadas, de forma privada e coletiva, e a pluralidade de significados das linguagens circulantes nesses discursos.

\section{Gêneros discursivos}

Além de se compreender a noção de multiletramentos, é relevante elucidar que as práticas de leitura e escrita multimodais só ocorrem por intermédio dos gêneros discursivos (BAKHTIN, 1997). Nesse sentido, concebe-se que a linguagem é uma atividade social e interativa (MARCUSCHI, 2008) que se materializa por meio dos gêneros discursivos, que são elaborados em cada esfera da atividade humana e entendidos, portanto, a partir do conteúdo temático, isto é, o conteúdo do texto acompanhado da apreciação de valor do locutor; do estilo verbal, que são as escolhas relativas ao vocabulário, à sintaxe e a outros aspectos gramaticais; e da construção composicional, que, conforme Rojo e Barbosa (2015), refere-se às formas de organização e acabamento do texto, como coesão, coerência e progressão temática.

Ainda segundo Rojo e Barbosa (2015), foram os filósofos Platão e Aristóteles que inauguraram a discussão a respeito do conceito de "gênero" ao refletirem sobre poética e retórica na Grécia Antiga. Tais reflexões foram ampliadas, no século XX, por Mikhail Bakhtin, Valentin Volochinov, Pavel Medvédev, entre outros que, juntos, integraram o que se denomina de Círculo de Bakhtin, isto é, "uma escola do pensamento russo do século XX, 
centrada na obra de Bakhtin” (ROJO; BARBOSA, 2015, p. 39). Para Marcuschi (2008), no Ocidente, há pelo menos vinte e cinco séculos, os gêneros já são objeto de estudo, porém o que temos, na atualidade, é um novo olhar para esta temática que está para além da discussão literária e presente em várias perspectivas disciplinares, como a sociologia, a etnografia, a antropologia, a retórica, a linguística etc.

Além de Estética da criação verbal, segundo Brait e Pistori (2012), outras produções de Bakhtin ou do Círculo de Bakhtin (dada a dificuldade de atribuição autoral) também abordam os gêneros discursivos - para além da caracterização relativa ao conteúdo temático, à composição e ao estilo - e colaboram, assim, no melhor entendimento desse conceito que é muito relevante para se pensar a leitura e a produção de textos no espaço escolar. Ao citarem a obra Problemas da poética de Dostoiévski, por exemplo, cuja $2^{a}$ edição data de 1963 , as autoras apontam que nela há:

importantes afirmações sobre gênero que respondem questões colocadas hoje em relação aos gêneros próprios das novas formas de comunicação, viabilizadas pela tecnologia e, especialmente, por novos valores assumidos pelo homem contemporâneo em relação a tempo/espaço, público/privado, efêmero/duradouro (BRAIT; PISTORI, 2012, p. 376).

Essas considerações, em alusão a tal obra de 1963, referem-se aos gêneros surgidos recentemente que se ancoram em gêneros anteriores. Essa ancoragem se dá pelo fato de que os gêneros se desenvolvem a partir de práticas sociais em transformação, logo, eles não surgem do vácuo, mas de práticas existentes na sociedade. Brait e Pistori (2012) ressaltam que essa tradição na qual o gênero se insere precisa ser levada em consideração e exemplificam essa discussão ao evidenciarem a ligação entre gêneros, típicos de suportes digitais, como o blog e o chat, e aqueles que foram antecessores a estes, como o diário íntimo e a carta. As autoras ainda reforçam que as proposições do Círculo de Bakhtin não se referem apenas às obras literárias, mas também às diversas produções de linguagem do dia a dia. No caso desta pesquisa, entende-se que, embora a multimodalidade não seja novidade, os 
gêneros surgidos nas práticas atuais carregam em si um arranjo multissemiótico mais expressivo, tendo em vista a "nova paisagem semiótica” (KRESS; VAN LEEUWEN, 2001).

\section{Metodologia}

Do ponto de vista metodológico, cabe destacar que

O objetivo dos investigadores qualitativos é o de melhor compreender o comportamento e experiência humanos. Tentam compreender o processo mediante o qual as pessoas constroem significados e descrever em que consistem estes mesmos significados. (BOGDAN; BIKLEN, 1994, p. 70).

Por essa razão, como o intuito desta investigação foi compreender o modo como os sujeitos se comportam e interagem em certo contexto (no caso, em aulas de Língua Portuguesa), a natureza desta pesquisa foi qualitativa. Sendo assim, a prática de uma professora do referido componente curricular foi acompanhada num intervalo de tempo de seis meses, compreendidos nos últimos meses de 2015 e nos primeiros de 2016. Nesse período, ela lecionou para três turmas de alunos que cursavam, respectivamente, o $8^{\circ}$ e o $9^{\circ}$ ano do Ensino Fundamental, em uma escola municipal, localizada na cidade de Ouro Preto (Minas Gerais) ${ }^{14}$.

Para a coleta de dados, foram utilizados os seguintes procedimentos:

I) observação participante, que, segundo Lüdke e André (1986), ocupa um lugar privilegiado nas abordagens de pesquisa educacional por possibilitar o contato direto do observador com o fenômeno estudado; descobrir novos aspectos de um problema; recorrer a experiências e conhecimentos pessoais na compreensão do problema investigado e coletar informações em que não é possível outra forma de comunicação ou mesmo quando a pessoa não quer fornecê-las;

${ }^{14}$ Tendo em vista a expressiva quantidade de informações coletadas no período citado, foi selecionado, como objeto deste estudo, um total de quatro aulas, referente à época em que a professora lecionava para as turmas do $8^{\circ}$ ano, em 2015. 
II) diário de campo, no qual se registraram informações, como: o que ocorreu, quando aconteceu, quem disse, o que foi falado, que mudanças aconteceram no contexto etc. Por meio do diário, também foram coletados materiais que circularam em sala de aula produzidos pela docente ou pelos próprios educandos;

III) registros de áudio das falas dos sujeitos pesquisados, por intermédio de um gravador de voz disponível no celular do pesquisador. Essas falas também foram transcritas segundo a norma-padrão da língua portuguesa ${ }^{15}$.

A apresentação dos dados coletados para análise deu-se por meio de um evento de letramento que, de acordo com Heath (1982), é qualquer ocasião na qual um material escrito integra a interação e os processos interpretativos de sujeitos. Nesse mesmo sentido, para Barton e Hamilton (2000, p. 8, tradução nossa), os eventos de letramento são “episódios observáveis que surgem a partir de práticas e são moldados por elas"16. A respeito da análise, concebeu-se, conforme afirma Luna (2004, p. 32), que “o referencial teórico de um pesquisador é um filtro pelo qual ele enxerga a realidade, sugerindo perguntas e indicando possibilidades". Portanto, o olhar interpretativo e analítico para tais dados, na busca de evidenciar possibilidades e desafios inerentes à prática docente, foi guiado à luz das teorias a respeito dos multiletramentos e dos gêneros discursivos aplicadas ao ensino de Língua Portuguesa.

\section{Evento de letramento: produção de marcador de página}

O foco desta seção é caracterizar o evento de letramento que ocorreu no contexto investigado, durante uma sequência composta por quatro aulas, e que foi escolhido para discussão deste estudo: a produção de marcadores de página.

Na primeira aula, a educadora explicou a tarefa a ser realizada e entregou a cada estudante das turmas do $8^{\circ}$ ano uma folha com orientações a respeito da atividade. De

\footnotetext{
${ }^{15}$ A investigação foi aprovada pelo Comitê de Ética da universidade à qual está vinculada, tendo, portanto, autorização, para divulgação, desse órgão, assim como dos participantes pesquisados.

16 "episodes which arise from practices and are shaped by them" (HAMILTON, 2000, p. 8).
} 
modo geral, nessa folha, havia um roteiro com a explicação de que os alunos deveriam ler quatro livros, anotar as referências bibliográficas das obras, e, para cada uma destas, produzirem um marcador de página. Além disso, essa explicação recebida pelos educandos continha os componentes do marcador: i. ilustração; ii. título do livro; iii. nome do autor; iv. texto escrito curto que poderia ser em forma de resumo, resenha ou sinopse; v. referência bibliográfica. A diferença entre resumo, resenha e sinopse também estava apresentada na folha, assim como o passo a passo para construção da referência bibliográfica. Para consolidação da atividade, os discentes também deveriam apresentar oralmente, para os colegas, o que foi produzido, no dia estipulado pela professora.

Nas orientações por escrito, ainda se enfatizou a ação de divulgar os livros lidos por intermédio dos marcadores, com o intuito de incentivar os colegas a realizarem a leitura da obra indicada. Além dessas informações contidas na folha e resumidas acima, a docente entregou um modelo de marcador de página para os alunos similar ao da imagem da Figura 1:

Figura 1: Modelo de marcador de página entregue pela professora

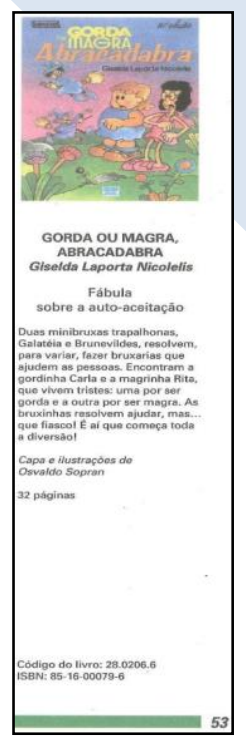

Fonte: Arquivo do pesquisador. 
Tendo esses dois materiais em mãos (folha de orientação e modelo de marcador de página), a professora conduziu discursivamente a explicação sobre o trabalho em questão e ressaltou que o marcador a ser elaborado pelos estudantes poderia ser similar ao entregue (Figura 1), e, inicialmente, a discussão girou em torno do formato do gênero em questão. A leitura desse marcador de página entregue não foi realizada, pois cada aluno recebeu um que apresentava uma obra específica, mas a educadora pediu para que os educandos o observassem.

Ainda sem usar o quadro para algum tipo de anotação, ela explicou que o marcador poderia ser feito em formato digital, por meio do programa $W$ ord, por exemplo, ou no formato manual. Sobre o formato, ela disse: "Coloquem a imagem, capa do livro, ilustração; mais texto; mais referência" (Fonte: Diário de campo do dia 28/10/2015). Nesse tipo de explicação, segurando também um modelo de marcador de página similar ao entregue aos alunos, a docente também apontou a presença desses itens de composição no marcador de página em mãos. Os estudantes questionaram-na sobre a possibilidade de retirar a capa do livro lido na internet e a educadora respondeu que isso poderia ser feito e, além da capa, eles poderiam escolher uma personagem ou uma cena marcante da história como ilustração de fonte digital ou desenhada, no caso de confeccionar o marcador manualmente.

Além disso, ela deixou circular pela sala outros exemplos de marcadores de livros que selecionou para mostrar aos discentes. Esses marcadores (do arquivo pessoal da educadora) ora seguiam o padrão do exemplo que os educandos já tinham recebido, ora tinham um formato diferenciado, com variação de cores, estilos, formato de letras, layout, entre outros aspectos verbo-visuais. Ela ainda comentou que os alunos poderiam usar um material mais resistente nessa produção escrita e, inclusive, podiam produzir em papel sulfite e colar em uma cartolina, por exemplo.

Em continuidade às explicações, no quadro, a professora passou o seguinte esquema: 
Figura 2: Reprodução do esquema passado no quadro pela docente

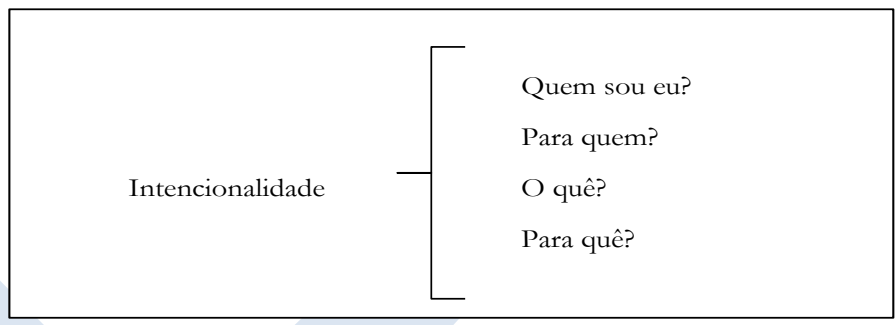

Fonte: Diário de campo do dia 28/10/2015.

Nesse esquema, a professora baseou-se, em suas afirmativas, na teoria que diz respeito às condições de produção textual. No contexto, ela disse que o texto a ser produzido pelos alunos do $8^{\circ}$ ano (“Quem?”) eram para os colegas de classe (“Para quem?”) e que estes itens, juntos ao "O quê?” e "Para quê?”, permitir-lhe-iam saber se o texto produzido seria ou não uma cópia da web. Desse modo, iniciou-se uma discussão na qual a educadora disse que, dada a "situação do discurso" (termo usado por ela), era possível saber se eles realmente fizeram o texto ou se copiaram de algum site. Associamos a não explicação da professora quanto ao "O quê?" e "Para quê?" pelas idas e vindas do discurso oral, em que muitas vezes não há uma linearidade e fechamento do pensamento, mas também pelas interrupções das falas dela devido a perguntas ou conversas paralelas dos alunos.

Na segunda aula, a docente retomou o trabalho nas turmas, lançando mão de outras estratégias para explicar novamente a atividade, embora a aula não tivesse esse tópico como principal objeto de discussão. Nessa retomada, um esquema foi feito no quadro, conforme se vê na Figura 3: 
Figura 3: Reprodução do esquema passado no quadro pela professora

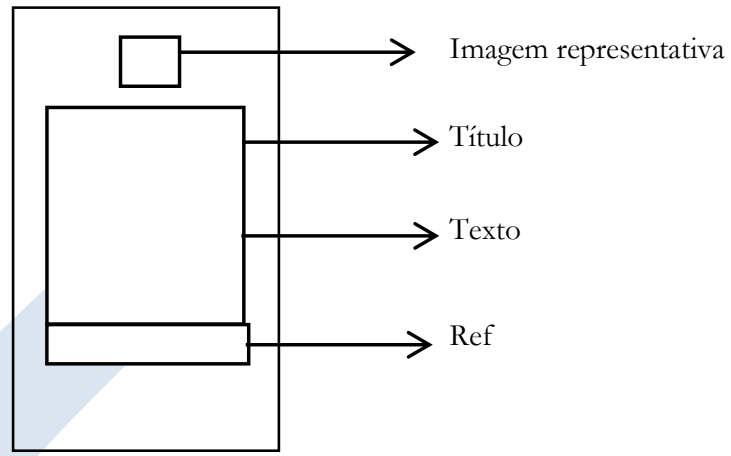

Fonte: Diário de campo do dia 04/11/2015.

Por meio desse esquema, a discente relembrou os elementos que compõem o marcador de página, mas também pontuou a disposição desses no layout: o espaço superior destinada à ilustração, o espaço central e de maior dimensão destinado ao título e ao texto escrito, e, por último, no fim do desenho, a parte destinada às referências bibliográficas que foram abreviadas por ela como "Ref.".

Transcorridas algumas semanas, na terceira aula, os alunos deveriam entregar os marcadores de página produzidos por cada um deles, além de apresentarem oralmente um dos livros que serviram de base na produção do marcador. Para organizar esse momento, a educadora passou, no quadro, um roteiro para nortear as apresentações orais daquele dia, com perguntas como: Qual o título do livro? Quem é o autor? Qual o assunto tratado no livro? Você indicaria o livro para outros leitores?, entre outras.

Na Figura 4, são apresentados alguns dos marcadores de página elaborados pelos discentes. As produções foram confeccionadas em diferentes papeis e eram digitais ou manuais, a partir de diferentes recursos, como uso de lápis, canetas coloridas, lápis de cor, giz de cera, colagens, imagens da internet etc.: 
Figura 4: Exemplos de marcadores de página produzidos pelos alunos
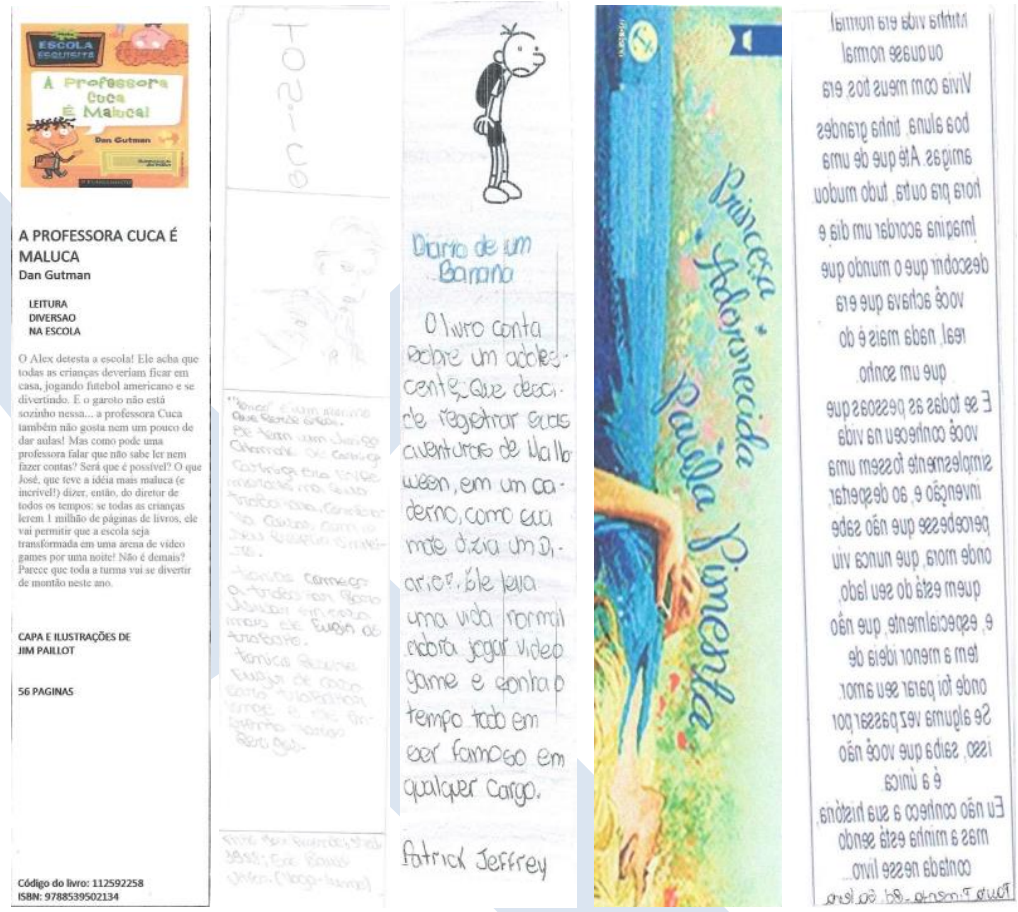

Fonte: Arquivo do pesquisador.

O primeiro exemplo de marcador foi produzido de modo tão fiel ao modelo entregue pela professora (cf. Figura 1) que foi feito com o código do livro, já que os modelos entregues compunham um catálogo de obras literárias para venda. A educadora chegou a questionar a aluna sobre o porquê de ter inventado um código e o inserido no marcador, e, como argumento, a estudante disse que seguiu a orientação docente e se baseou no modelo entregue.

Ainda naquele dia, cada educando contou um pouco sobre o livro escolhido e algumas dessas narrativas foram construídas com bastantes detalhes, inclusive com a reprodução das falas de personagens. Isso mostrou a leitura cuidadosa e o real envolvimento de alguns discentes com a atividade. Além de terem o direito de fala ao narrar a história, alguns 
alunos, após ouvirem o colega, também comentaram e compararam aquela narrativa ao filme produzido e adaptado da obra. Isso aconteceu, por exemplo, quando um educando sintetizou a coletânea de livros da saga Harry Potter (J. K. Rowling) e também discutiu divergências e convergências entre esta e os filmes de mesmo título. Naquele momento, a professora disse que se tratava de duas linguagens diferentes e que era muito interessante o fato de os próprios alunos estabelecerem esse tipo de comparação. Além de Harry Potter, os livros $A$ culpa é das estrelas (Josh Boone) e a trilogia Jogos Vorazes (Suzanne Collins) também foram citados pelos estudantes que falaram: da proximidade do livro com o filme, da ausência de detalhes e/ou acontecimento no filme baseado no livro, ou da preferência que tinham pela obra escrita ou pela adaptação cinematográfica.

$\mathrm{Na}$ quarta aula, seis alunos foram selecionados por sorteio para distribuírem, em conjunto, os marcadores entre as turmas de $8^{\circ}$ ano e as demais salas da escola do turno da manhã. A educadora levou um cesto no qual depositou todos os marcadores e discentes fizeram a distribuição que efetivou a real circulação do gênero discursivo produzido pelas três turmas. No retorno dos estudantes para sala, a professora comentou a respeito da atratividade de uns marcadores em detrimento de outros: os marcadores mais bem elaborados e chamativos foram os primeiros a acabarem. Na sala de aula, foi perceptível que os alunos queriam ter para si os marcadores cuja composição visual estava bem construída e articulada. Outro fator de maior interesse, nesse processo de escolha, era o livro em discussão contido no marcador: os best-sellers mais comentados no universo estudantil também os atraíram.

\section{Análise das possibilidades e dos desafios em prol dos multiletramentos}

Primeiramente, pode-se depreender, a respeito do evento de letramento apresentado, que a prática da docente esteve articulada a discussões teóricas sobre o ensino de língua materna na atualidade, já que a exploração dos usos da leitura não se voltou apenas à linguagem verbal - de modo tradicional e monolíngue (COPE; KALANTZIS, 2006), 
pois houve espaço para a discussão em torno das linguagens que permeiam as práticas letradas.

Outra questão importante foi que a professora organizou o ensino da língua a partir da seleção de um gênero discursivo. Como não podemos nos comunicar sem ser por meio deles (BAKHTIN, 1997), percebemos que a prática docente é estruturada a partir do gênero, como sugerem pesquisadores como Rojo (2009) e Marcuschi (2011), assim como consta nos Parâmetros Curriculares Nacionais (BRASIL, 1998) e na Base Nacional Comum Curricular (BRASIL, 2017). Além disso, o foco não esteve restrito a habilidades de leitura e de escrita somente, pois se buscou expandir as práticas de letramento do alunado considerando a produção de sentidos multimodais situados contextualmente.

Isso ficou visível, por exemplo, quando a educadora não deixou de explicitar o gênero discursivo a ser produzido pelos alunos (marcador de página), o conteúdo temático (texto sintético sobre uma obra literária), os objetivos para as quais este será produzido (divulgar o livro lido e estimular que outros o leiam) e o público a que se destinava (colegas de classe). Embora o marcador de página também possa ser entendido como um suporte textual, o analisamos como gênero discursivo multimodal, uma vez que a leitura de tal gênero exige compreensão das linguagens que o constituem e também pelo fato de a professora o ter tratado como tal.

No objetivo de produzir o marcador, houve um antecedente que foi a leitura das obras literárias, pois os alunos também as leram considerando que socializariam oralmente as leituras e as impressões para os colegas, mas também por escrito, por meio da circulação desse texto multimodal que atingiria um público ainda maior (demais turmas da escola). Soma-se a essa preocupação com as finalidades da leitura e da escrita, o fato de os educandos terem produzidos os marcadores para um público real; além de terem tido contato com outros exemplos do gênero que circularam socialmente, isto é, no objetivo fim de produzir o marcador, existiram outros objetivos anteriores, como o incentivo à literatura, a discussão do gênero e o estímulo à oralidade. 
Por outro lado, se pensarmos nos multiletramentos, houve um episódio passível de discussão e que, certamente, é um desafio para muitos educadores: a professora apresentou, em tal situação, uma concepção tradicional de que os educandos não poderiam copiar informações da internet na hora de redigir o texto escrito. Nessa perspectiva, a escrita dos alunos seria uma ferramenta de vigilância por parte da docente, que desconsidera as possibilidades de remixagem. Aqui cabe relembrar que, na perspectiva dos multiletramentos, devemos ser e formar designers de significado, isto é, a partir dos recursos semióticos disponíveis (available designs), temos o trabalho de transformá-los em significados (designing) cujo resultado (redesigned) nunca é mera repetição do que já tinha sido produzido (COPE; KALANTZIS, 2006).

Quanto à multimodalidade, pode-se afirmar que a professora a concebeu como a combinação de linguagens. Ela explorou e valorizou outras linguagens que não apenas a verbal na escrita dos marcadores, quando discutiu, por exemplo, o que seria uma imagem representativa da obra e o que comporia o gênero, assim como dissertou sobre a distribuição dos itens estruturadores do gênero dentro do limite disponível no layout a ser criado.

Destacamos a originalidade dessa proposta docente, tendo em vista que o marcador de página não tem sido um gênero de estudo nos livros didáticos de Língua Portuguesa, dada a nossa experiência enquanto professores e pesquisadores desse componente curricular. Inclusive, antes de analisarmos este evento de letramento, ainda não tínhamos nos dado conta das potencialidades de exploração didática do gênero, já que, como dito, ele é multimodal por excelência e permite uma produção textual que venha a circular em contextos sociais reais. Soma-se a isso o fato de a educadora ter conectado a escrita do marcador à literatura, isto é, a outro eixo de ensino, o que evidenciou também um modo de se trabalhar a leitura literária de uma forma não tradicional. Apesar de todos esses aspectos positivos, temos ciência de que tal gênero não é tão comum de ser produzido, mas, no contexto investigado, cumpriu uma função social, sendo, portanto, de relevância para os participantes. 
Uma estratégia interessante presente na prática docente foi a ação de levar, para a sala de aula, exemplos reais do gênero discursivo em estudo (e não usar fotocópias, por exemplo, nas quais se perderia a diversidade das cores). Com os exemplos, que funcionaram como um recurso didático-pedagógico, os alunos puderam visualizar arranjos multimodais diferenciados, tanto do ponto de vista das linguagens e efeitos visuais que os constituem, quanto do material do qual foram feitos. Isso porque esses marcadores foram construídos com variadas cores, disposições e construções de texto verbal, ilustrações, assim como tinham formatos diferentes. Além desses aspectos, como aponta van Leeuwen (2006), a tipografia, que também é um modo semiótico, apresenta variações quanto ao tamanho, tipo, espessura e inclinação da letra. Há ainda a questão do suporte material desse gênero, por exemplo, se estava em um papel mais resistente ou não, o que interfere muito na produção de um marcador, pois a ideia é que este tenha maior durabilidade, tendo em vista que veicula informações, mas também serve como "registro" da última página lida de um livro impresso, por exemplo.

Os esquemas e os desenhos passados no quadro pela professora também colaboraram para um melhor entendimento sobre a produção dos marcadores de página. É importante destacar que esses recursos, embora sejam típicos de aulas expositivas e estejam inseridos na sala de aula há anos, também evidenciam a existência da multimodalidade, já que, ao usá-los, a educadora não fez uso apenas da escrita de palavras. Ribeiro (2014) menciona isso ao apontar que, há muito tempo, professores escrevem, mas também desenham em lousas sem as tecnologias modernas que temos hoje.

Nesse sentido, esquemas, como aquele no qual constavam os elementos a serem considerados dentro das condições de produção do marcador (cf. Figura 2), também foram recursos empregados na organização e compreensão da atividade a ser realizada. No esquema com o layout do gênero (cf. Figura 3), a professora também listou os itens (imagem representativa, título, texto e referência) que precisariam estar presentes no marcador, assim como evidenciou a ordem a qual estes deveriam estar nele. Além disso, no desenho, aparece uma distribuição espacial de cada um desses itens na totalidade do layout do gênero, o que 
Cope e Kalantzis (2009) denominam de representação espacial, a qual, evidentemente, possibilita o reconhecimento do gênero e traz sentidos que precisam ser interpretados pelo leitor (DIONISIO, 2011).

Entre os desafios do evento de letramento, ressaltamos que os livros literários também podem ser um material para exploração multimodal no processo de ensino-aprendizagem, posto que literatura goza de privilégios na combinação de linguagens, como a verbal e a visual (DIONISIO, 2011). Por isso, Moraes (2015) argumenta que a leitura literária, independentemente de ser em suporte digital ou impresso, destinada ao público infantil ou não, requer habilidades leitoras no tocante à multimodalidade. Sendo assim, é significativa a discussão a respeito das linguagens presentes nas capas das obras ou no interior destas, quando há.

Como mencionado anteriormente, a professora permitiu a circulação, nas salas de aula, de vários tipos de marcadores de página que ela tinha em seu arquivo pessoal. Ela também entregou a cada um dos estudantes um modelo que ele guardou consigo. Apesar de o recebimento desse material ter sido válido, já que compreendemos que a leitura de um gênero precede a escrita deste, destacamos um mal-entendido que tal marcador exemplo provocou entre os participantes, pois, no modelo (cf. Figura 1), na parte inferior, aparece um código numérico para o livro resenhado. Esse código consta no marcador porque a docente o retirou de um catálogo cujo objetivo é vender livros. Logo, tendo uma finalidade diferente daquela que teriam os alunos, a composição do gênero era outra, pois deveria permitir que um leitor pudesse escolher uma obra de seu interesse e comprá-la, a partir de um determinado código que facilitasse esse processo de compra e venda. Decorre disso o fato de uma aluna produzir os marcadores com códigos fictícios, conforme se observa na Figura 4, e a educadora questioná-la sobre a necessidade de uso de tal código.

Dessa forma, compreendemos que, naquele contexto, embora tenha sido fundamental a utilização de marcadores exemplos como material de exploração do gênero, era necessária uma explicação oral que pontuasse essa diferença entre o marcador entregue e aquele a ser produzido pelos discentes. A professora fez uma adequação do gênero, já que 
os alunos não venderiam os livros que leram, mas estimulariam a leitura de determinada obra. Contudo faltou enfatizar que a função do marcador exemplo e a do marcador a ser produzido não eram similares, pois, no primeiro caso, o valor é publicitário e extremamente persuasivo, com a finalidade de divulgar e vender; no segundo, o valor é mais convidativo, com o intuito de incentivar a leitura no contexto escolar. Mas, em ambos os casos, há um valor mais secundário do marcador que é sua função literal enquanto um utilitário. Enfim, é fato que tal episódio reforça o que apresentam Ribeiro (2014) sobre a centralidade da figura do professor enquanto importante mediador do processo de ensino-aprendizagem, sobretudo quando se trata da multimodalidade atrelada às práticas sociais das quais participamos.

A fala em que a docente citou a necessidade de haver uma imagem no marcador suscitou dúvidas dos alunos, pois eles a questionaram se a ilustração representativa do livro, como a capa, poderia ser retirada da internet. Ao responder afirmativamente esse questionamento, a educadora também destacou que outras representações visuais poderiam ser escolhidas além da capa, como a figura de uma personagem ou a de uma cena relevante da história. Ao analisar isso, compreendemos que essas falas da docente foram uma contribuição sobre os usos da escrita multimodal, já que alertaram os alunos sobre o que seria uma representação visual representativa de uma obra literária e que, portanto, merecia destaque na divulgação da história lida.

Foi na explicação oral também que a professora comentou sobre a possibilidade de os educandos usarem formatos criativos e papel mais resistentes na produção do marcador. Além disso, ela também sugeriu uma solução aos discentes que, por questões financeiras ou ausência de recursos digitais, fariam o marcador manualmente: eles poderiam produzilo em papel sulfite e colá-lo em uma cartolina depois, a fim de ficar mais resistente.

A partir disso, podemos inferir que a produção de um marcador no universo escolar, além de ter levado a uma alteração da finalidade do gênero, implicou uma mudança de tecnologias e de recursos usados no processo de elaboração, sugerida pela própria educa- 
dora. Sendo assim, sem a possibilidade de usar um computador, por exemplo, os educandos lançaram mão do lápis, da caneta, do giz de cera etc. Além disso, se compararmos a escrita de um marcador digital com a de um manual, veremos que o espaço para a linguagem verbal, por exemplo, no segundo caso, é menor, já que se utiliza um maior espaço para a escrita manual. Logo, houve modificações na composição desse gênero discursivo multimodal tendo em vista necessidades adaptativas que o contexto exigiu e, na prática docente, é preciso orientar mais os alunos quanto a isso, para que eles tenham criticidade e bom senso e consigam realizar a produção textual de modo legível e com uma estética apropriada (diferente do marcador produzido a lápis) (cf. Figura 4).

Apesar disso, não podemos esquecer que, como defende Ribeiro (2016), em um momento de produção textual, a seleção de fazê-la em um ambiente digital ou não está sujeita às finalidades e às necessidades do produtor. Acrescemos a essa ideia a questão de as possibilidades de que dispunham os alunos de imprimir ou não os marcadores feitos digitalmente, mas que não foi colocada como impedimento, posto que a docente sugeriu maneiras alternativas de produzir o marcador manualmente.

Outra interação discursiva que merece destaque aconteceu durante a socialização das leituras. Para além da discussão sobre o enredo das obras e sobre os aspectos que os discentes relataram terem chamado ou não a atenção deles, a comparação entre obras e filmes foi outra possibilidade em que a multimodalidade foi alvo de discussão entre os participantes, também motivada pela fala de um educando que apresentou a saga Harry Potter (J. K. Rowling). A partir da fala dele, a educadora discursou que o livro e o filme são duas linguagens diferentes e que esse olhar comparativo dos alunos era interessante. Em seguida, outros estudantes citaram outros livros que foram adaptados para a linguagem cinematográfica, como $A$ culpa é das estrelas (Josh Boone) e a trilogia Jogos Vorazes (Suzanne Collins), e discutiram convergências e divergências entre essas duas linguagens, assim como opinaram se gostavam mais do livro ou do filme. Essa interação verbal também possibilitou o contraste entre duas linguagens que possuem potenciais de representações específicos e que, embora possam carregar significados semelhantes, estes jamais são iguais, exatamente 
pela diferenciação dos modos semióticos que as compõem (COPE; KALANTZIS, 2009). Ou seja, essa discussão suscitada pelos próprios discentes e pontuada pela educadora foi uma oportunidade de se discutir a linguagem audiovisual, nesse caso, cinematográfica, que lida com imagens em movimento, cores e efeitos audiovisuais, em contraponto com o arranjo do livro físico.

Para finalizar a análise do evento de letramento caracterizado, cabe relembrar a fala da professora no momento em que os alunos distribuíram os marcadores pela escola. Tal docente comentou que os marcadores mais bem elaborados e chamativos foram os primeiros a acabar, o que evidenciou a importância do arranjo visual de um gênero multimodal impresso como este, já que ele objetiva atrair consumidores (no caso comercial) ou leitores (no caso escolar). Essa finalidade pode ser mais bem alcançada se a linguagem visual, em integração à verbal, está esteticamente organizada e chamativa. Nesse sentido, é fundamental que isso também seja abordado na discussão do gênero em sala de aula.

\section{Considerações finais}

Pode-se afirmar que a prática de escrita mediada pela professora se deu por meio de um gênero discursivo que foi abordado numa perspectiva multimodal. Nesse sentido, esta investigação revelou possibilidades (tangentes aos materiais utilizados em sala de aula, às explicações orais e escritas, às metodologias de ensino, às concepções da educadora subjacentes às práticas escolares) de se trabalhar com os multiletramentos, por meio de uma sequência de atividades promovidas de forma autoral e criativa, em um contexto real de produção textual.

Além disso, foi possível apontar desafios (e não erros ou impedimentos) que devem ser observados nesse processo, como a didatização de um gênero que pode acarretar alterações na finalidade social do texto, assim como nas tecnologias e nos recursos utilizados na escrita. Também se corroborou a necessidade de se trabalhar adequadamente a leitura crítica de um gênero, antes de solicitar a produção deste, para que os educandos sejam mais proficientes nas práticas letradas. 
Por fim, os dados analisados reforçaram a centralidade e a relevância do papel do educador de Língua Portuguesa que precisa explorar os gêneros discursivos sem restringir tal trabalho apenas à linguagem verbal. Logo, a prática docente atual requer um novo olhar sobre a paisagem semiótica (KRESS; VAN LEEUWEN, 2001) que forme cidadãos multiletrados, mais bem preparados para se engajarem no mundo do trabalho, na vida pública e nos modos de vida pessoal (COPE; KALANTZIS, 2006).

\title{
MULTILITERACIES IN PRODUCTION OF BOOKMARK DISCURSIVE GENRE
}

\begin{abstract}
This study, based on the theories of multiliteracies and the discursive genres, aimed to characterize and analyze how a Portuguese-speaking teacher explored the writing of the multimodal discursive genre bookmark, during literacy event, with students from the final years of elementary school. Thus, it was intended to problematize possibilities and challenges that emerge from practices of this nature in favor of multiliteracies. From the methodological point of view, the investigation took place through the participant observation of a teacher's practice in three the $8^{\text {th }}$ grade of Primary School, in a public school in Ouro Preto (Minas Gerais). From this, it was noticeable to understand didactic and discursive possibilities, for example, regarding the valuation of multiple languages in a social practice of production of a discursive genre composed of a graphic-visual project. In addition, it was possible to discuss inherent obstacles to the multiliteracies practices in Portuguese language teaching, such as the schooling of a discursive genre, which implies changes in technologies and resources used in writing processes.
\end{abstract}

KEYWORDS: Portuguese language classes; Discursive genre; Bookmark; Multiliteracies.

\section{REFERÊNCIAS}

BAKHTIN, M. Estética da criação verbal. 2. ed. São Paulo: Editora Martins Fontes, 1997. BARTON, D.; HAMILTON, M.; IVANIC, R. Situated Literacies: reading and writing in context. Routledge: Londres, 2000.

BOGDAN, R.; BIKLEN, S. Investigação qualitativa em Educação: uma introdução à teoria e aos métodos. Tradução de Maria João Alvarez, Sara Bahia dos Santos e Telmo Mourinho Baptista. Portugal: Porto Editora, 1994.

BRASIL. Parâmetros Curriculares Nacionais Lingua Portuguesa: terceiros e quartos ciclos do Ensino Fundamental. Secretaria de Educação Fundamental. Brasília: Ministério da Educação, 1998. Disponível em: < http://portal.mec.gov.br/seb/arquivos/pdf/portugues.pdf>. Acesso: 03 jan. 2017. 
. Base Nacional Comum Curricular. Educação é a Base. Brasília, MEC/CON-

SED/UNDIME, 2017. Disponível em: <https://goo.gl/9QzJGq >. Acesso: 11 nov. 2018.

BRAIT, B.; PISTORI, M. H. C. A produtividade do conceito de gênero em Bakhtin e o Círculo. Alfa, São Paulo, 56 (2), 2012, p. 371-401.

COPE, B.; KALANTZIS, M. (Orgs). Multiliteracies: Literacy Learning and the Design of Social Futures. London/New York: Routledge, 2006. 425, 2009 .

A grammar of multimodality. International Journal of Learning, v. 16, n. 2, p. 361-

DIONISIO, A. P. Gêneros textuais e multimodalidade. In: KARWOSKI, A. M.; GAYDECZKA, B.; SIEBENEICHER, K. (Orgs.). Gêneros textuais: reflexões e ensino. 4. ed. São Paulo: Parábola Editorial, 2011, p. 135-152.

HEATH, S. B. What no bedtime story means: Narrative skills at home and school. Language in Society, 11(1), 1982, p. 49-76.

KRESS, G.; VAN LEEUWEN, T. Reading images: the gramar of visual design. 5. ed. London; New York: Routledge, 2001.

LÜDKE, M.; ANDRÉ, M. Pesquisa em educação: abordagens qualitativas. São Paulo: EPU, 1986.

LUNA, S. V. O falso conflito entre tendências metodológicas. In: FAZENDA, I. (Org.). Metodologia da pesquisa educacional. 9. ed. São Paulo: Cortez, 2004, p. 21-33.

MARCUSCHI, L. A. Produção textual, análise de gêneros e compreensão. São Paulo: Parábola Editorial, 2008.

Gêneros textuais: configuração, dinamicidade e circulação. In: KARWOSKI, A. M.; GAYDECZKA, B.; SIEBENEICHER, K. (Orgs.). Gêneros textuais: reflexões e ensino. 4. ed. São Paulo: Parábola Editorial, 2011, p. 17-31.

MORAES, G. L. Do livro ilustrado ao aplicativo: reflexões sobre multimodalidade na literatura para crianças. Estudos de literatura brasileira contemporânea, n. 46, jul./dez. 2015, p. 231-253.

RIBEIRO, A. E. Tecnologias na educação: questões e desafios para a produção de sentido. Revista Práticas de Linguagem, v. 4, n. 2, 2014, p. 152-158.

. Textos multimodais: leitura e produção. São Paulo: Parábola Editorial, 2016.

ROJO, R. Letramentos múltiplos, escola e inclusão social. São Paulo: Parábola Editorial, 2009. ; BARBOSA, J. P. Hipermodernidade, multiletramentos e gêneros discursivos. São Paulo: Parábola Editorial, 2015. 
STREET, B. V. Multimodalidade. In: FRADE, I. C. A.; VAL, M. G. C.; BREGUNCI, M. G. C. (Orgs.). Glossário Ceale: termos de alfabetização, leitura e escrita para educadores. Belo Horizonte: Ed. UFMG, 2014. Disponível em: < http://ceale.fae.ufmg.br/app/webroot/glossarioceale/verbetes/multimodalidade>. Acesso: 06 jul. 2019.

VAN LEEUWEN, T. Towards a semiotics of typography. Information Design Journal - Document Design, n. 14, 2006, p. 139-145.

Recebido em: 10/12/2019.

Aprovado em: 20/01/2020. 